\title{
Countertraction applied using clips and a rubber band: a new simple method for cannulation of intradiverticular or hidden papillae
}

A juxtapapillary diverticulum is a frequent age-related condition that may affect $10 \%-20 \%$ of patients undergoing endoscopic retrograde cholangiopancreatography, and increases the prevalence of stones in the principal bile duct [1]. This can render biliary duct cannulation difficult. Papillae can also be hidden by lipomas, gastrointestinal stromal tumors, or mucosal folds. To facilitate cannulation, the two-devices-in-one-channel technique of Fujita et al. can be used. A pediatric biopsy forceps is employed to evert the papilla out of the diverticulum, and other devices are inserted in parallel, in the operative channel [2]. The principal drawback is the poor maneuverability of both the duodenoscope and the elevator. Scotiniotis et al. used a clip to apply traction (the weight of the clip) to the papilla [3]. This allowed for good scope maneuverability but traction was minimal; the papilla remained unstable. We here report two cases of difficult biliary access ( Video 1).
A 78-year-old woman was referred because of abdominal pain and abnormal liver function test results. An intracholedochal stone was evident on endoscopic ultrasonography ( $\triangleright$ Fig.1). The intradiverticular papilla could not be cannulated ( $\triangleright$ Fig. 2). We used the clip plus rubber band strategy previously employed during endoscopic submucosal dissection [4] to apply countertraction; this exposed the papilla well in the axis of the infundibulum. First, a dental rubber band was placed on the tip of a rotating re-openable clip and inserted via the duodenoscope. The clip was placed on the peridiverticular mucosa and the rubber band was grasped with a second clip that was placed on the third part of the duodenum to establish continuous countertraction ( $\triangleright$ Fig.3). Given the good papillary exposure, biliary cannulation, sphincterotomy, and balloon removal of the stone proceeded uneventfully. Although some bleeding was noted, this was treated via mechanical balloon com-

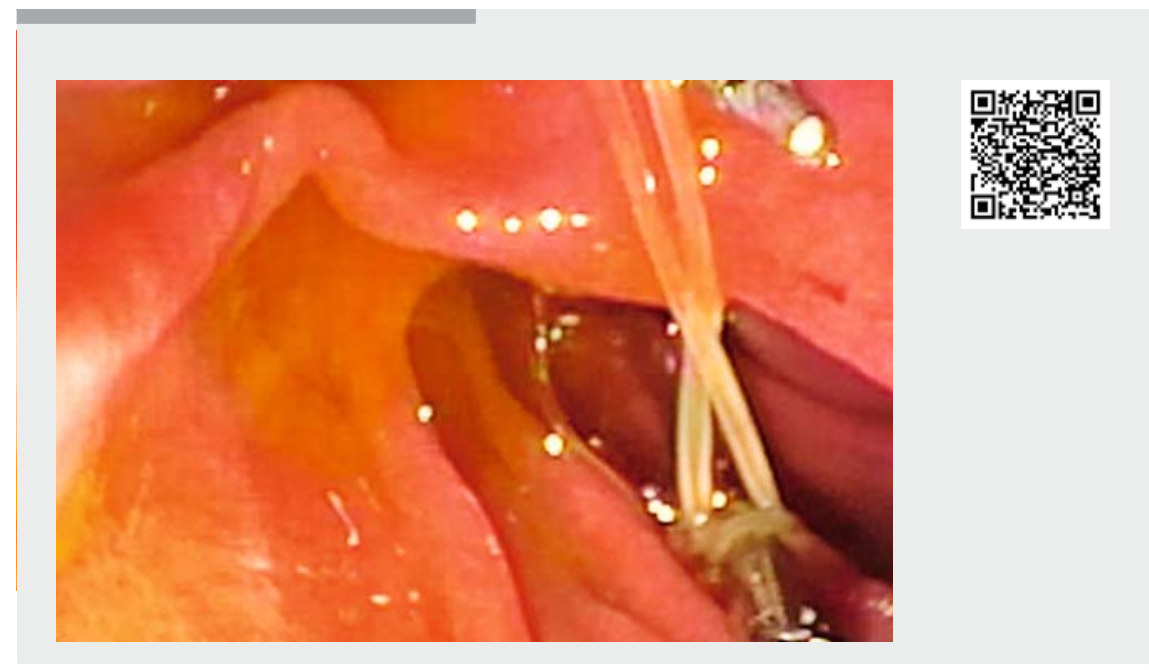

$\checkmark$ Video 1 Two cases of countertraction applied with clips and rubber band to improve exposure of the papilla. 


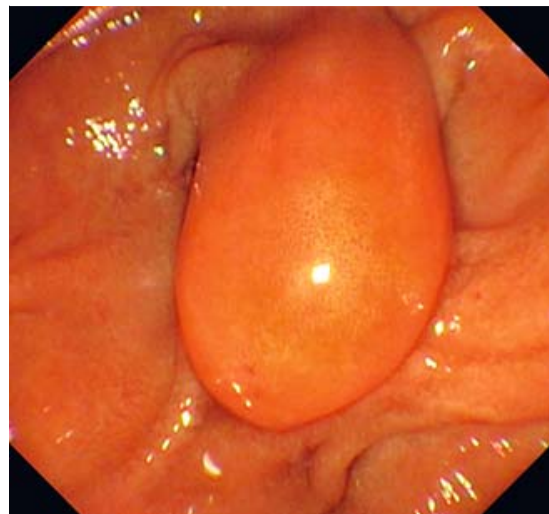

Fig. 4 Lipoma hiding the papilla.

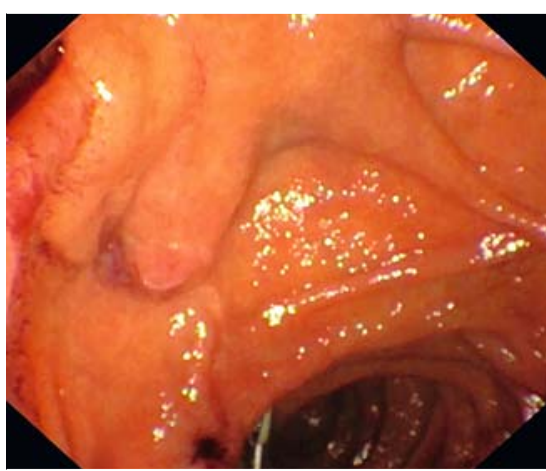

- Fig. 5 Everted lipoma and accessible papilla.

pression and insertion of a fully covered self-expandable metal stent.

Our second case was a 65-year-old man with cholangitis and a stone evident on computed tomography. He underwent duodenoscopy but a lipoma concealed the papilla despite changing the patient's position $>$ (Fig. 4). We applied the countertraction described above to place the head of the lipoma in the duodenal bulb; this ensured excellent papillary exposure ( $>$ Fig. $\mathbf{5}$ ).

In summary, clip plus rubber band countertraction effectively exposes intradiverticular or hidden papillae. Traction is continuous and steady, the duodenoscope and elevator can move freely, and the suction channel is fully functional, which is essential to counter bleeding.

Endoscopy_UCTN_Code_TTT_1AR_2AC

\section{Competing interests}

None

\section{The authors}

Marion Schaefer ${ }^{1}$, Bastien Dirrenberger ${ }^{1}$, Mathilde Morin ${ }^{1}$, Arthur Belle ${ }^{1}$, Sophie Gueyl$^{2}$, Jérémie Jacques ${ }^{2,3}$, Jean-Baptiste Chevaux ${ }^{1}$

1 Service d'Hépato-gastro-entérologie, CHU de Nancy, Vandoeuvre-lès-Nancy, France

2 Service d'Hépato-gastro-entérologie, $\mathrm{CHU}$ Dupuytren, Limoges, France

3 BioEM, UMR 7252, CNRS, Limoges

\section{Corresponding author}

\section{Marion Schaefer, MD}

Service d'Hépato-gastro-entérologie, $\mathrm{CHU}$ de Nancy, Rue du Morvan, 54500

Vandoeuvre-lès-Nancy, France

Fax: +33-3-83153633

mrn.schaefer@gmail.com

\section{References}

[1] Egawa N, Anjiki H, Takuma K et al. Juxtapapillary duodenal diverticula and pancreatobiliary disease. Dig Surg 2010; 27: 105-109

[2] Fujita N, Noda Y, Kobayashi G et al. ERCP for intradiverticular papilla: two-devices-inone-channel method. Endoscopic retrograde cholangiopancreatography. Gastrointest Endosc 1998; 48: 517-520

[3] Scotiniotis I, Ginsberg GG. Endoscopic clipassisted biliary cannulation: externalization and fixation of the major papilla from within a duodenal diverticulum using the endoscopic clip fixing device. Gastrointest Endosc 1999; 50: $431-433$

[4] Jacques ], Charissoux A, Legros R et al. Double-clip counter-traction using a rubber band is a useful and adaptive tool for colonic endoscopic submucosal dissection. Endoscopy 2018; 50: 179-181

\section{Bibliography}

DOI https://doi.org/10.1055/a-0958-9265

Published online: 16.7.2019

Endoscopy 2019; 51: E386-E387

(c) Georg Thieme Verlag KG

Stuttgart · New York

ISSN 0013-726X

\section{ENDOSCOPY E-VIDEOS}

https://eref.thieme.de/e-videos

口回 Endoscopy E-Videos is a free rection, reporting 回: on interesting cases and new techniques in gastroenterological endoscopy. All papers include a high quality video and all contributions are freely accessible online.

This section has its own submission website at https://mc.manuscriptcentral.com/e-videos 